\title{
Effects of calcium hydroxide addition on the physical and chemical properties of a calcium silicate-based sealer
}

\author{
Milton Carlos KUGA', Marco Antonio Hungaro DUARTE², Arnaldo SANT'ANNA-JÚNIOR², Kátia Cristina KEINE', \\ Gisele FARIA ${ }^{1}$, Andrea Abi Rached DANTAS ${ }^{1}$, Flávia Angélica GUIOTTI ${ }^{1}$
}

1- Department of Restorative Dentistry, Araraquara Dental School, UNESP - Univ. Estadual Paulista, Araraquara, SP, Brazil.
2- Department of Dentistry, Endodontics and Dental Materials, Bauru School of Dentistry, University of São Paulo, Bauru, SP, Brazil.

Corresponding address: Milton Carlos Kuga - Departamento de Odontologia Restauradora, Faculdade de Odontologia de Araraquara, Univ. Estadual Paulista - Rua Humaitá, 1680 - Araraquara - SP - Brazil - 14.801-903 - Phone (+55) 1633016396 - e-mail: kuga@foar.unesp.br

Submitted: January 8, 2013 - Modification: January 18, 2014 - Accepted: February 19, 2014

\section{ABSTRACT}

\begin{abstract}
R ecently, various calcium silicate-based sealers have been introduced for use in root Rcanal filling. The MTA Fillapex is one of these sealers, but some of its physicochemical properties are not in accordance with the ISO requirements. Objective: The aim of this study was to evaluate the flowability, $\mathrm{pH}$ level and calcium release of pure MTA Fillapex (MTAF) or containing $5 \%$ (MTAF5) or $10 \%$ (MTAF10) calcium hydroxide $(\mathrm{CH})$, in weight, in comparison with $\mathrm{AH}$ Plus sealer. Material and Methods: The flowability test was performed according to the ISO 6876:2001 requirements. For the $\mathrm{pH}$ level and calcium ion release analyses, the sealers were placed individually $(n=10)$ in plastic tubes and immersed in deionized water. After 24 hours, 7 and 14 days, the water in which each specimen had been immersed was evaluated to determine the $\mathrm{pH}$ level changes and calcium released. Flowability, $\mathrm{pH}$ level and calcium release data were analyzed statistically by the ANOVA test $(\alpha=5 \%)$. Results: In relation to flowability: MTAF $>A H$ Plus $>M T A F 5>M T A F 10$. In relation to the $p H$ level, for $24 \mathrm{~h}$ : MTAF5=MTAF10 $=$ MTAF $>$ AH Plus; for 7 and 14 days: MTAF5=MTAF $10>M T A F>A H$ Plus. For the calcium release, for all periods: MTAF $>$ MTAF5 $=$ MTAF10 $>A H$ Plus. Conclusions: The addition of 5\% $\mathrm{CH}$ to the MTA Fillapex (in weight) is an alternative to reduce the high flowability presented by the sealer, without interfering in its alkalization potential.
\end{abstract}

Keywords: Calcium hydroxide. Dental cements. Endodontics. Physical and chemical properties. Silicate cement.

\section{INTRODUCTION}

Mineral trioxide aggregate (MTA) was developed to be used in endodontic complications, as well as in apical surgery ${ }^{20,25}$. Actually, it is also recommended to be used in pulp conservative treatments and in obturation of the apical portion of immature teeth ${ }^{11,22}$.

MTA induces a new apical cementum deposition when used in root canals ${ }^{16}$. However, its handling is difficult for use in root canal obturations ${ }^{5}$. Several calcium silicate-based sealers were developed to be used as a root canal filling material, such as Endo-CPM-Sealer (EGEO, Temperley, Buenos Aires, Argentina), ProRoot Endo Sealer (Dentsply Maillefer, Ballaigues, Switzerland) and an experimental cement, MTAS ${ }^{3,13}$. Recently, a new formulation of MTA-based cement (MTA Fillapex; Angelus Indústria de Produtos Odontológicos S.A., Londrina, Paraná, Brazil) was created to be used as a root canal sealer ${ }^{14}$. The composition of MTA Fillapex after mixing is MTA, salicilate resin, natural resin, bismuth and silica, according to the manufacturer.

MTA Fillapex has an antibacterial effect against $E$. faecalis before setting and adequate biocompatibility ${ }^{11,21}$. Despite these biological properties, its physicochemical properties are controversial. MTA Fillapex had the lowest push-out values to root dentine compared with $\mathrm{AH}$ Plus and IRoot SP sealers ${ }^{26}$. But in another study, MTA Fillapex presented acceptable resistance to dislodgement, which was similar to $\mathrm{AH}$ Plus ${ }^{1}$. A possible reason 
for this different result can be attributed to the difficulty in handling due to excessive flowability. This observation was previously confirmed in a pilot study.

Adequate flowability is a necessary property of endodontic sealers ${ }^{4}$. Excessive flowability can favor apical extrusion and injure the periapical tissue, mainly in teeth with a wide foraminal opening ${ }^{15,26,28}$. A suggestion in order to decrease the flowability is the addition of calcium hydroxide into the sealer ${ }^{8}$.

On the other hand, the ideal endodontic sealer should be biocompatible and able to induce mineralized tissue formation. These properties are directly associated with the alkalization potential and calcium release of the materials ${ }^{10}$. Calcium hydroxide provides an alkaline $\mathrm{pH}$ and calcium ion release, leading to biochemical effects that culminate in the acceleration of the repair process ${ }^{27}$. The MTA Fillapex sealer (Angelus) has an alkaline $\mathrm{pH}$ and promotes calcium release ${ }^{19}$. However, the effects of the addition of calcium hydroxide into MTA Fillapex with the objective of reducing sealer flowability are unknown.

The aim of this study was to evaluate the flowability, $\mathrm{pH}$ level and calcium ion release of MTA Fillapex, with the addition of $5 \%$ or $10 \%$ calcium hydroxide powder (in weight), compared to pure MTA Fillapex and AH Plus.

\section{MATERIAL AND METHODS}

\section{Root canal sealers}

The sealers used in this study were: $\mathrm{AH}$ Plus (Dentsply DeTrey, Konstanz, Germany) and the MTA Fillapex (MTAF) (Angelus Indústria de Produtos Odontológicos S.A., Londrina, Paraná, Brazil). The MTAF was used pure or with the addition of $5 \%$ (MTAF5) or $10 \%$ (MTAF10) calcium hydroxide (Labsynth, Diadema, São Paulo, Brazil), in weight. For the AH Plus, the base and catalyst pastes were used in equal parts, in the proportion of $1: 1(\mathrm{w} / \mathrm{w})$.

\section{Flowability}

The root canal sealers were mixed according to conditions recommended by the manufacturer and the flowability test was performed according to the ISO 6876:2001 requirements ${ }^{4,18}$.

\section{Sample preparation}

Forty polyethylene tubes measuring $10 \mathrm{~cm}$ in length and $1.5 \mathrm{~mm}$ in internal diameter were filled with the sealers to be evaluated. For the $\mathrm{pH}$ level and calcium ion release evaluation, 10 samples were prepared from each material studied. Immediately after manipulating the materials, the tubes were filled and weighed to check the standardization of the amount of sealer in each tube $( \pm 0.002 \mathrm{~g})$ and placed in polypropylene flasks (Injeplast, São Paulo,
São Paulo, Brazil) containing $10 \mathrm{~mL}$ of deionized water. The tubes were kept at $37^{\circ} \mathrm{C}$ (Fanem, São Paulo, São Paulo, Brazil) during the entire study. After 24 h, 7 and 14 days, the water was assessed for $\mathrm{pH}$ levels and calcium release. Previous to the immersion of the specimens, the $\mathrm{pH}$ level and calcium ion concentration of the deionized water were verified, attesting a $\mathrm{pH}$ level of 6.8 and a total absence of calcium ions. The tubes containing the sealers were placed in new flasks with $10 \mathrm{~mL}$ of deionized water for further analyses in the different time periods.

pH level test and calcium release analysis

Measurements were performed with a $\mathrm{pH}$ meter Q400AS (Quimis, Diadema, São Paulo, Brazil) in constant temperature $\left(25^{\circ} \mathrm{C}\right)$. After $24 \mathrm{~h}$ of immersion, the tubes were carefully removed and placed into another flask with an equal amount of new deionized water. This procedure was repeated for a total of $336 \mathrm{~h}$ with the solution changed at 24 $\mathrm{h}, 7$ and 14 days. The $\mathrm{pH}$ values were compared by the ANOVA and Tukey tests, at a 5\% significance level.

The calcium release was measured using an AA7000 atomic absorption spectrophotometer (Shimadzu, Nakaygio-ku, Kyoto, Japan), in accordance to the manufacturer's instructions. For the reading, $6 \mathrm{~mL}$ of the standard solutions or water samples were associated with $2 \mathrm{~mL}$ of lanthanum nitrate solution. For the white solution, $6 \mathrm{~mL}$ of deionized water was associated with the same amount of lanthanum nitrate solution. With the standard solutions, the white solutions and the prepared sample, the reading was carried out using an atomic absorption spectrophotometer ${ }^{29}$. The

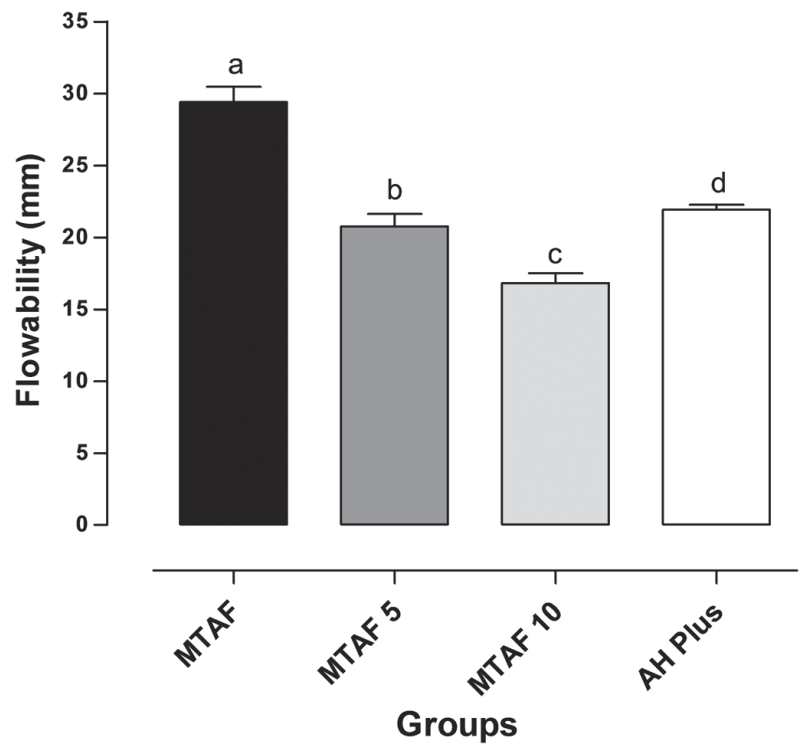

Figure 1- Flowability values from each sealer evaluated (in $\mathrm{mm}$ ). Different letters indicate statistically significant differences $(p<0.05)$ 
calcium release was calculated by the equation of the line of the standard curve. The reading of the calcium release was taken in the same periods used for measuring the $\mathrm{pH}$ level. The calcium release values were compared by the ANOVA and Tukey tests, at a $5 \%$ significance level.

\section{RESULTS}

The representative mean and standard deviation for flowability values from each sealer are presented in Figure 1 (in $\mathrm{mm}$ ). MTAF showed higher flowability $(29.4 \mathrm{~mm})$ than the other sealers $(p<0.05)$.

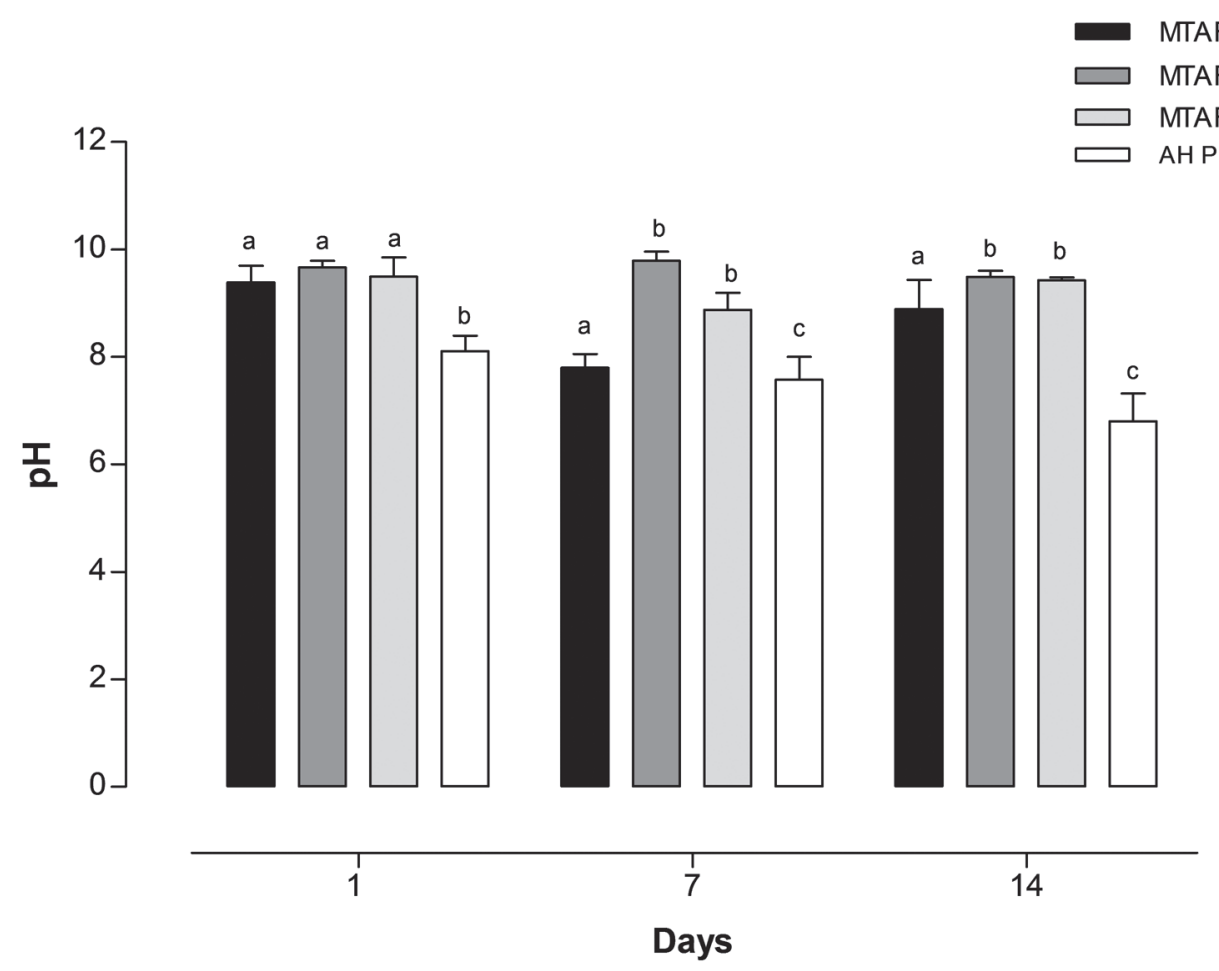

Figure 2- $\mathrm{pH}$ from each sealer studied in the different experimental periods. Different letters indicate statistically significant differences $(p<0.05)$

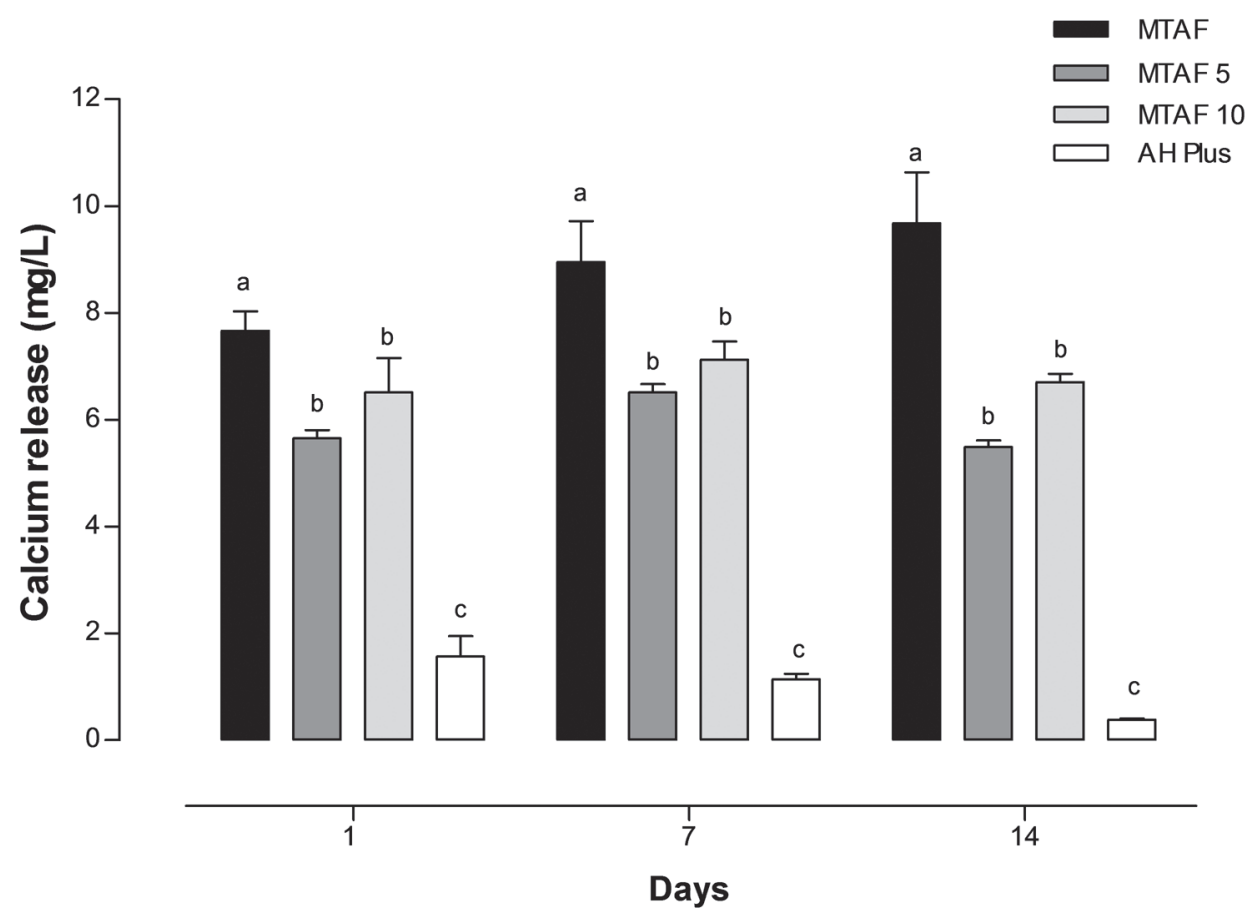

Figure 3- Calcium release (mg/L) from each sealer studied in the different experimental periods. Different letters indicate statistically significant differences $(p<0.05)$ 
The flowability of the MTAF5 was lower than the MTAF and AH Plus ( $p>0.05)$; however, it was in accordance with the ISO 6876:2001 requirements.

The MTAF10 showed the lowest flowability in relation to the other sealers $(p<0.05)$ and this value was below the ISO 6876:2001 requirements $(p<0.05)$. The flowability means and standard deviations (in mm) for the MTAF, MTAF5, MTAF10 and AH Plus were 29.40 (1.05), 20.75 (0.89), 16.80 (0.71) and $21.91(0.36)$, respectively.

The representative mean and standard deviation of $\mathrm{pH}$ values and calcium release from each sealer in different periods are presented in Figures 2 and 3, respectively. For all periods, the AH Plus showed the lowest $p H$ value $(p<0.05)$. At $24 h$, the MTAF, MTAF5 and MTAF10 showed similar pH values $(p>0.05)$. At 7 and 14 days, the MTAF5 and MTAF10 showed similar $\mathrm{pH}$ values $(\mathrm{p}>0.05)$ and higher $\mathrm{pH}$ level than the MTAF $(p<0.05)$.

For all periods, the AH Plus showed the lowest means of calcium release $(p<0.05)$. On the other hand, the MTAF5 and MTAF10 showed similar calcium release $(p>0.05)$ and lower calcium release than the MTAF.

\section{DISCUSSION}

The addition of $5 \%$ calcium hydroxide to the MTAF provided a reduction of the flowability, in accordance with ISO requirements. Its $\mathrm{pH}$ level was alkaline in all periods but the calcium release was lower than pure MTA Fillapex. Despite the addition of $10 \%$ calcium hydroxide to MTA Fillapex, it provided a reduction in flowability, and this mixture is in disagreement with the ISO 6876:2001 requirements.

The flowability test results revealed that the addition of calcium hydroxide provides a reduction in flowability of the MTAF. This can be explained by an increase in the powder/liquid ratio also promoted, in accordance with that observed in a previous study ${ }^{23}$. Except for the MTAF10, all sealers were in accordance with the ISO 6876:2001 requirements ${ }^{18}$.

It has been suggested that in order to stimulate mineralization, a material should have an alkaline $\mathrm{pH}$ level and calcium release ${ }^{10}$. The methodologies used for the $\mathrm{pH}$ level and calcium release evaluations were similar to other studies ${ }^{6,19,31}$. The MTAF5 and MTAF10 presented pH levels similar to the MTAF, but only in a $24 \mathrm{~h}$ period. After this time, the $\mathrm{pH}$ values were higher than any other sealer.

For all periods, the MTAF showed a higher calcium release despite the fact that calcium hydroxide was added in the MTAF5 and MTAF10. Hosoya, et al. ${ }^{17}$ (2004) observed that the addition of $10 \%$ calcium hydroxide in some sealers causes variations in setting time. Therefore, the addition of calcium hydroxide in the MTAF could also have reduced the setting time of the sealer and consequently its solubility, consequently reducing the calcium release. In contrast with this result, the addition of calcium hydroxide did not alter the AH Plus setting time ${ }^{8}$. However, the compositions of these sealers are different. AH Plus sealer presented lower calcium release than the other sealers, although it contains tungstate calcium in its composition. These results are consistent with other studies also carried out with atomic absorption spectrophotometry ${ }^{7,12}$.

Through a comparative analysis of the compositions described by the manufacturers, it was observed that the MTAF and Sealapex (SybronEndo, Orange, California, USA) contain several similar substances in their formulations. Thus, it is possible that many reactions and effects described in the Sealapex also occur with the MTAF. Eldeniz, et al. ${ }^{9}$ (2007) report that a possible reason for the high calcium release provided by the Sealapex is related with the presence of $24 \%$ calcium hydroxide. Since the sealer has a porous matrix with a low dimensional stability and high water absorption, the calcium is easily released 2,24 .

On the other hand, the addition of substances with calcium in the MTA promotes a reduction of the setting time $^{30}$. Thus, the addition of calcium hydroxide in the MTAF could have interfered in the setting time and consequently in the calcium release. This could be a possible reason for the higher calcium release presented by MTAF when compared to the MTAF5 and MTAF10.

MTA has established properties and indications for use in several endodontic procedures ${ }^{25}$. Its use as an endodontic sealer requires further adjustments, since its handling is very difficult. MTAF is a new calcium silicate-based sealer whose flowability is in accordance with the ISO 6876:2001 requirements ${ }^{18}$; clinically, however, it is very high, which can favor the extrusion of the material to the apical tissues. The purpose of adding $5 \%$ calcium hydroxide (in weight) to the total weight of the sealer is to obtain an adequate alternative. Further studies are necessary to biologically evaluate this purpose.

\section{CONCLUSION}

Based on the methods and conditions employed in the present study, it is concluded that the addition of $5 \%$ calcium hydroxide (in weight) to the MTAF provides a reduction in the flowability of the sealer, in conditions required by the ISO 6876:2001 specifications and favors a higher alkaline $\mathrm{pH}$. 


\section{REFERENCES}

1- Assmann E, Scarparo RK, Böttcher DE, Grecca FS. Dentin bond strength of two mineral trioxide aggregate-based and epoxy resinbased sealers. J Endod. 2012;28:219-21.

2- Caicedo R, von Fraunhofer JA. The properties of endodontic sealer cements. J Endod. 1988;14:527-34.

3- Camilleri J, Gandolfi MG, Siboni F, Prati C. Dynamic sealing ability of MTA root canal sealer. Int Endod J. 2011;44:9-20. 4- Camps J, Pommel L, Bukiet F, About I. Influence of the powder/ liquid ratio on the properties of zinc oxide-eugenol-based root canal sealers. Dent Mater. 2004;20:915-23.

5- Cintra LT, Moraes IG, Estrada BP, Gomes-Filho JE, Bramante CM, Garcia DB, et al. Evaluation of the tissue response to MTA and MBPC: microscopic analysis of implants in alveolar bone of rats. J Endod. 2006;32:556-9.

6- Duarte MA, Demarchi AC, Giaxa MH, Kuga MC, Fraga SC, Souza LC. Evaluation of $\mathrm{pH}$ and calcium ion release of three root canal sealers. J Endod. 2000;26:389-90.

7- Duarte MA, Oliveira-Demarchi AC, Moraes IG. Determination of $\mathrm{pH}$ and calcium ion release provided by pure and calcium hydroxide containing $\mathrm{AH}$ Plus. Int Endod J. 2004;37:42-5.

8- Duarte MA, Ordinola-Zapata R, Bernardes RA, Bramante CM, Bernardineli N, Garcia RB, et al. Influence of calcium hydroxide association on the physical properties of $\mathrm{AH}$ Plus. J Endod. 2010;36:1048-51.

9- Eldeniz AU, Erdemir A, Kurtoglu F, Esener T. Evaluation of pH and calcium ion release of Acroseal sealer in comparison with Apexit and Sealapex sealers. Oral Surg Oral Med Oral Pathol Oral Radiol Endod. 2007;103:e86-91.

10- Estrela C, Sydney GB, Bammann LL, Felippe Júnior O. Mechanism of action of calcium and hydroxyl ions of calcium hydroxide on tissue and bacteria. Braz Dent J. 1995;6:85-90.

11- Felippe WT, Felippe MC, Rocha MJ. The effect of mineral trioxide aggregate on the apexification and periapical healing of teeth with incomplete root formation. Int Endod J. 2006;39:2-9.

12- Flores DS, Rached-Júnior FJ, Versiani MA, Guedes DF, SousaNeto MD, Pécora JD. Evaluation of physicochemical properties of four root canal sealers. Int Endod J. 2011;44:126-35.

13- Gomes-Filho JE, Watanabe S, Bernabé PF, Moraes Costa MT. A mineral trioxide aggregate sealer stimulated mineralization. ] Endod. 2009;35:256-60.

14- Gomes-Filho JE, Watanabe S, Lodi CS, Cintra LT, Nery MJ, Filho JA, et al. Rat tissue reaction to MTA Fillapex $®$. Dent Traumatol. 2012;28:452-6.

15- Holland $R$, Sant'Anna-Júnior $A$, Souza $V$, Dezan Júnior $E$, Otoboni Filho JA, Bernabé PF, et al. Influence of apical patency and filling material on healing process of dogs' teeth with vital pulp after root canal therapy. Braz Dent J. 2005;16:9-16.
16- Holland R, Souza V, Nery MJ, Otoboni Filho JA, Bernabé PF, Dezan Júnior $E$. Reaction of dogs' teeth to root canal filling with mineral trioxide aggregate or a glass ionomer sealer. J Endod. 1999;25:728-30.

17- Hosoya N, Kurayama H, Iino F, Arai T. Effects of calcium hydroxide on physical and sealing properties of canal sealers. Int Endod J. 2004;37:178-84.

18- International Organization for Standardization. ISO 6876:2001: Dental root canal sealing materials. Geneva: ISO; 2001.

19- Kuga MC, Campos EA, Viscardi PH, Carrilho PZ, Xaviér FC, Silvestre NP. Hydrogen ion and calcium releasing of MTA Fillapex and MTA-based formulations. RSBO. 2011;8:271-6.

20- Lee SJ, Monsef M, Torabinejad M. Sealing ability of mineral trioxide aggregate for repair of lateral root perforations. J Endod. 1993;19:541-4.

21- Morgental RD, Vier-Pelisser FV, Oliveira SD, Antunes FC, Cogo DM, Kopper PM. Antibacterial activity of two MTA-based root canal sealers. Int Endod J. 2011;44:1128-33.

22- Nair PN, Duncan HF, Pitt Ford TR, Luder HU. Histological, ultrastructural and quantitative investigations on the response of healthy human pulps to experimental capping with mineral trioxide aggregate: a randomized controlled trial. Int Endod J. 2008;41:128-50.

23- Ostarvik D. Physical properties of root canal sealers: measurements of flow, working time, and compressive strength. Int Endod J. 1983;16:99-107.

24- Ørstavik D, Nordahl I, Tibballs JE. Dimensional change following setting of root canal sealer materials. Dental Materials. 2001; 17:12-9.

25- Parirokh M, Torabinejad M. Mineral trioxide aggregate: a comprehensive literature review--Part III: Clinical applications, drawbacks, and mechanism of action. J Endod. 2010;36:400-13. 26- Sagsen B, Ustün $Y$, Demirbuga $S$, Pala K. Push-out bond strength of two new calcium silicate-based endodontic sealers to root canal dentine. Int Endod J. 2011;44:1088-91.

27- Seux D, Couble ML, Hartmann DJ, Gauthier JP, Magloire H. Odontoblast-like cytodifferentiation of human dental pulp cells in vitro in the presence of a calcium hydroxide-containing cement. Arch Oral Biol.1991;36:117-28.

28- Suzuki P, Souza V, Holland R, Murata SS, Gomes-Filho JE, Dezan Júnior $E$, et al. Tissue reaction of the EndoREZ in root canal fillings short of or beyond an apical foramen like communication. Oral Surg Oral Med Oral Path Oral Rad Endod. 2010;109:e94-9. 29- Vasconcelos BC, Bernardes RA, Cruz SM, Duarte MA, Padilha $\mathrm{PM}$, Bernardineli $\mathrm{N}$, et al. Evaluation of $\mathrm{pH}$ and calcium ion release of new root-end filling materials. Oral Surg Oral Med Oral Pathol Oral Radiol Endod. 2009;108:135-9.

30- Wiltbank KB, Schwartz SA, Schindler WG. Effects of selected accelerants on the physical properties of mineral trioxide aggregate and Portland cement. J Endod. 2007;33:1235-8. 